\begin{tabular}{|l|l|l|}
\hline \multicolumn{2}{|c|}{ PublisherInfo } \\
\hline \hline PublisherName & $:$ & BioMed Central \\
\hline \hline PublisherLocation & $:$ & London \\
\hline \hline PublisherImprintName & $:$ & BioMed Central \\
\hline \hline
\end{tabular}

\title{
Monocyte chemoattractant protein 1 promotes autoimmune injury
}

\begin{tabular}{|l|l|l||}
\hline \multicolumn{2}{|c|}{ ArticleInfo } \\
\hline \hline ArticleID & $:$ & 211 \\
\hline \hline ArticleDOI & $:$ & $10.1186 /$ ar-2000-66774 \\
\hline \hline ArticleCitationID & $:$ & 66774 \\
\hline \hline ArticleSequenceNumber & $:$ & 168 \\
\hline \hline ArticleCategory & $:$ & Paper Report \\
\hline \hline ArticleFirstPage & $:$ & 1 \\
\hline \hline ArticleLastPage & $:$ & 3 \\
\hline \hline & & RegistrationDate : 2000-1-14 \\
\hline ArticleHistory & $:$ & OnlineDate \\
\hline \hline ArticleCopyright & $:$ & Current Science Ltd2000-14 \\
\hline \hline ArticleGrants & $:$ & \\
\hline \hline ArticleContext & $:$ & 130753311 \\
\hline \hline
\end{tabular}


Aff1 Imperial College School of Medicine, London, UK

\section{Keywords}

Chemokine, gene disruption, kidney, lung, mouse

\section{Context}

A series of reports suggests that monocyte chemoattractant protein (MCP)-1 may be responsible for inflammation in tissues during autoimmune disease. Indeed strategies that neutralise or eliminate MCP-1 are protective in induced models of inflammation. The phenotypic expression of autoimmune disease in MRL-Fas(lpr) mice is characterised by a large tissue infiltration of mononuclear leukocytes that is responsible for lymphadenopathy, splenomegaly, and autoimmune injury in multiple tissues, including kidney, lung and skin. The authors hypothesise that MCP-1 is responsible for recruiting macrophages and $\mathrm{T}$ cells and thereby for initiating disease in the kidney and other tissues undergoing autoimmune attack in MRL-Fas(lpr) mice. To construct an MCP-1-deficient MRL-Fas(lpr) strain of mouse and evaluate the role of MCP-1 in the pathology and survival of MRL-Fas(lpr) mice. To determine the mechanism responsible for leukocyte accumulation within tissues.

\section{Significant findings}

MCP-1 expression was increased in MRL-Fas(lpr) tissues during autoimmune disease, being mainly expressed by parenchymal cells in multiple tissues targeted for autoimmune injury. MCP-1-deficient MRL-Fas(lpr) mice live longer than MCP-1-intact MRL-Fas(lpr) strains, with 75\% of MCP-1-deficient MRL-Fas(lpr) mice still alive at 300 days compared with $17 \%$ of MCP- $1+/+$ and $44 \%$ of MCP $+/-$. From 2 to 8 months of age, the rate of increase and incidence of pathological proteinuria was diminished in MCP-1-deficient MRL-Fas(lpr) mice. Similarly the incidence and severity of lymphadenopathy and skin lesions were reduced, but not totally eliminated, in these mice. There was no difference in splenomegaly between MCP-1-deficient and MCP-1-intact MRL-Fas(lpr) mice. Histology revealed a dramatic (50-70\%) reduction in tubular and glomerular pathology in the kidneys of MCP-1-deficient MRLFas(lpr) mice, with a concomitant reduction in the number of apoptotic cells. However, the perivascular infiltrates in MCP-1-deficient and intact MRL-Fas(lpr) kidneys remained similar; thus, MCP-1 is responsible for tubular and glomerular but not perivascular renal pathology. Pulmonary disease was reduced, as shown by a dramatic reduction in the number of cells surrounding bronchioles in MCP-1-deficient mice. A decrease in the number of infiltrating macrophages and $\mathrm{T}$ cells was noted in 
MCP-1-deficient MRL-Fas(lpr) kidneys, whereas the lungs of these mice had a reduction only in infiltrating macrophages. In situ detection of PCNA revealed that this decrease in cell accumulation did not appear to be due to decreased local proliferation. Upon analysis of other MCPs and cytokines, MCP-3, MCP-5, CSF-1 and interferon (IFN)-? transcripts were all shown to be reduced in MCP-1-deficient MRL-Fas(lpr) kidneys. No differences in serum or kidney-deposited Igs was noted, and similarly $\mathrm{C} 3$ deposition was unaltered.

\section{Comments}

This paper very convincingly demonstrates that MCP-1 plays an important role in autoimmune tissue injury in MRL-Fas(lpr) mice, and elucidates that MCP-1 is key to the recruitment of leukocytes to tissues undergoing autoimmune disease. The striking improvement in disease severity in MCP-1-deficient mice highlights MCP-1 as a viable therapeutic target to combat autoimmune disease. However, as highlighted by the authors, additional therapeutic targets need to be identified to achieve more complete protection from autoimmune disease in MRL-Fas(lpr) mice.

\section{Methods}

MCP-1-deficient MRL-Fas(lpr) mice were created by a series of genetic backcrosses using the crossbackcross-intercross scheme and genotyped by polymerase chain reaction (PCR). Monthly assessments of proteinuria (dip-stick analysis), lymphadenopathy and skin lesions (scored 0 - 3) were carried out. Splenomegaly was determined by measuring spleen weight and histopathology was performed on kidneys and lungs. Immunostaining was used to identify infiltrating cells (as either T cells or macrophages) and to detect MCP-1 in tissues. The serum immunoglobulin (Ig) profile (total Ig, IgM, IgG1, IgG2a, IgG2? and IgG3) was measured by ELISA and IgG and C3 deposits in kidneys were assessed by immunofluorescence staining. Apoptotic cells were identified in tissue sections using the TUNEL method and proliferating cells were detected by proliferating cell nuclear antigen (PCNA) immunostaining. Detection of MCPs and cytokines in the kidney was also carried out by PCR.

\section{References}

1. Tesch GH, Maifert S, Schwarting A, Rollins BJ, Kelley VR: Monocyte chemoattractant protein 1-dependent leukocytic infiltrates are responsible for autoimmune disease in MRL-Fas(lpr) mice. J Exp Med. 2000, 190: 1813-1824.

This PDF file was created after publication. 